\title{
Length, strength and water flow: relative importance of wave and current exposure on morphology in kelp Laminaria hyperborea
}

\author{
Trine Bekkby ${ }^{1,2, *}$, Eli Rinde ${ }^{1}$, Hege Gundersen ${ }^{1,3}$, Kjell Magnus Norderhaug $^{1,4}$, \\ Janne K. Gitmark ${ }^{1}$, Hartvig Christie ${ }^{1}$ \\ ${ }^{1}$ Norwegian Institute for Water Research (NIVA), Gaustadalléen 21, 0349 Oslo, Norway \\ ${ }^{2}$ Geo-Ecology Research Group, Natural History Museum, and ${ }^{3}$ Centre for Ecological and Evolutionary Synthesis (CEES), \\ and ${ }^{4}$ Department of Biosciences, University of Oslo, 0316 Oslo, Norway
}

\begin{abstract}
Water flow is a strong determinant of kelp growth, but it is also a stress factor causing breakage and dislodgement. As wave exposure and currents differ with respect to flow pattern, the 2 forces are expected to affect kelp morphology differently. We investigated how wave exposure and current speed interact and influence kelp Laminaria hyperborea morphology. We sampled thalli from 27 stations on the Midwest coast of Norway and recorded age, and length- and strength-related characters. We found that high wave exposure and current speed influenced holdfast biomass and stipe thickness. Wave exposure had, overall, a stronger effect than current speed. An increase in current speed seemed to have a considerable effect at low wave exposure levels, but the relationship weakened at high wave exposure levels. The length-related ('go with the flow') characters thallus and stipe length were influenced by wave induced water flow but not by current speed. Differences in wave exposure and current speed had very weak influences on lamina biomass and length. Thus, the proportion of the thallus being lamina was high in the most sheltered areas and decreased as the wave exposure increased. Our study suggests that the strong, orbital and stochastic mode of wave exposure has a different and stronger effect as a stressor than the more regular and bidirectional stress caused by currents.
\end{abstract}

KEY WORDS: Physical disturbance $\cdot$ Stress $\cdot$ Water flow $\cdot$ Kelp morphology $\cdot$ Biomass $\cdot$ Size

\section{INTRODUCTION}

Water flow is a key environmental factor for macroalgae, both directly through environmental stress causing breakage and dislodgement and indirectly by affecting factors such as light levels and carbon metabolism (e.g. Wing \& Patterson 1993), photosynthesis and nutrient uptake (Wheeler 1988), transport across boundary layers (Raven 1981), settlement and recruitment (Vadas et al. 1990), resource allocation (Raven 1988) and growth (Hepburn et al. 2007). Many macroalga species show large variations in

\footnotetext{
*Corresponding author: trine.bekkby@niva.no
}

morphology as an adaptation to hydrodynamic forces (e.g. Hurd 2000 and references therein, Martone et al. 2012). Macroalga fronds are often wide and thin in more sheltered areas, maximising the surface to volume ratio and thus capturing more light and nutrients. In more exposed areas, the boundary diffusion layer is reduced by the water flow, thereby increasing the nutrient uptake and enhancing growth (Gerard 1982, Hurd et al. 1996). In exposed areas, fronds are often thick and streamlined, for protection against strong water forces (e.g. Fowler-Walker et al. 2006, Wernberg \& Vanderklift 2010). Studies have

() The authors 2014. Open Access under Creative Commons by Attribution Licence. Use, distribution and reproduction are unrestricted. Authors and original publication must be credited. 
shown variation in both length- and strength-related characters with water flow, with adaptations allowing the species to survive and grow in a wide range of exposure levels (Sultan 2001). Many kelp species show an increase in length-related characters, such as thallus, stipe and lamina length, with greater wave exposure (e.g. Wernberg \& Thomsen 2005, Wernberg \& Vanderklift 2010, Pedersen et al. 2012). This is considered an adaptation to orbital water flow, as a long and flexible thallus 'going with the flow' reduces hydrodynamic forces (Friedland \& Denny 1995, Denny et al. 1998, Koehl 1999). Studies have also shown greater strength-related characters, such as stipe thickness and holdfast size, with increasing water flow, reducing the risk of being dislodged (e.g. Koehl et al. 2008, Wernberg \& Vanderklift 2010).

Kelp forests dominate the rocky seabed in the temperate parts of the world and are highly productive systems (Mann 2000). The kelp Laminaria hyperborea (Gunnerus) Foslie is widely distributed in the northeast Atlantic, from Portugal $\left(\sim 37^{\circ} \mathrm{N}\right)$ in the south (Kain 1971a) to the Murman coast $\left(\sim 68^{\circ} \mathrm{N}\right)$ in the north (Schoschina 1997). In Norway, the species has optimal temperature and light conditions in the midNorway region, at $\sim 62^{\circ} \mathrm{N}$ (Rinde \& Sjøtun 2005). L. hyperborea dominates the subtidal, shallow $(<30 \mathrm{~m})$ and rocky seabed in exposed and moderately wave exposed areas (Kain 1971a, Bekkby et al. 2009). The 3-dimensional structure of the kelp forest functions as a habitat for high numbers of species and individuals of epiphytic algae and associated invertebrates and fish (Whittick 1983, Norderhaug et al. 2005). The importance of $L$. hyperborea as a habitat is related to its size and structural complexity (Christie et al. 2003, Norderhaug et al. 2007).

Several studies have documented the importance of wave exposure on L. hyperborea distribution, growth, density, production, biomass, mortality and morphology (e.g. Svendsen \& Kain 1971, Sjøtun \& Fredriksen 1995, Sjøtun et al. 1998, Bekkby et al. 2009, Pedersen et al. 2012). Few have studied the effect of current speed on this species (but see Bekkby et al. 2009 and the discussion in Kain 1971b), but such studies exist for other macroalgae species (e.g. Duggins et al. 2003, Eckman et al. 2003). The combination of tidal currents and the complex topography found in many regions along the Norwegian coast imply that current flow influences kelp growth and survival in these areas.

It is thought that macroalgae will respond to the total volume of water flow (Kregting et al. 2013). However, wave exposure and tidal currents differ as a physical stressor with respect to the pattern of water flow, i.e. the frequency, intensity and direction. Wave exposure is driven by wind conditions and is orbital and stochastic. The wave energy is at its maximum close to the sea surface, declining towards the sea bed (see Bekkby et al. 2008 and references therein). Tidal currents are more regular with respect to direction, intensity and frequency as they follow the tidal cycle. Tidal forces are more homogeneous with depth than wave exposure, even though friction at the seabed influences also ocean currents. It is, therefore, reasonable to assume that wave and current driven water flow affect kelp morphology differently. The objective of this study was to identify how the morphology of the kelp L. hyperborea sampled in the canopy layer vary with different levels of wave exposure and current speed.

\section{MATERIALS AND METHODS}

\section{Study area and sampling design}

Kelp Laminaria hyperborea thalli were collected from 27 stations in the Finnøy archipelago between 26 August and 2 September 2008 (Fig. 1). The study area is representative of the outer coast of midNorway, with small islands, underwater shallows and rocks. The area receives heavy waves and ocean swells from the Norwegian Sea to the west, leaving the eastern part of the study area less wave exposed, being sheltered by islands and underwater shallows. The study area has a tidal amplitude of $1.80 \mathrm{~m}$. The topography of the area, composed of islands, shallows, narrow sounds and adjacent fjords provides relatively large spatial differences in tidal current speed.

GIS models of wave and current exposure (see below) were used to find sampling stations representative of the range and different combinations of wave exposure and current speed levels within the area. To avoid differences in light and wave attenuation, we collected data at similar depths (5 m chosen from the bathymetric model and verified in the field). Stations were as similar as possible with respect to slope and aspect (i.e. orientation relative to solar influx), as these factors might influence light influx and kelp growth (Gorman et al. 2013). The stations were as similar as possible with respect to thallus density (based on models, Bekkby et al. 2009, and verified visually in the field), to avoid variations in crowding effects influencing the kelp measures (e.g. Hymanson et al. 1990, Wernberg 2005). We also ensured that the selected stations had not been harvested (using harvesting sector maps from FMC Bio- 

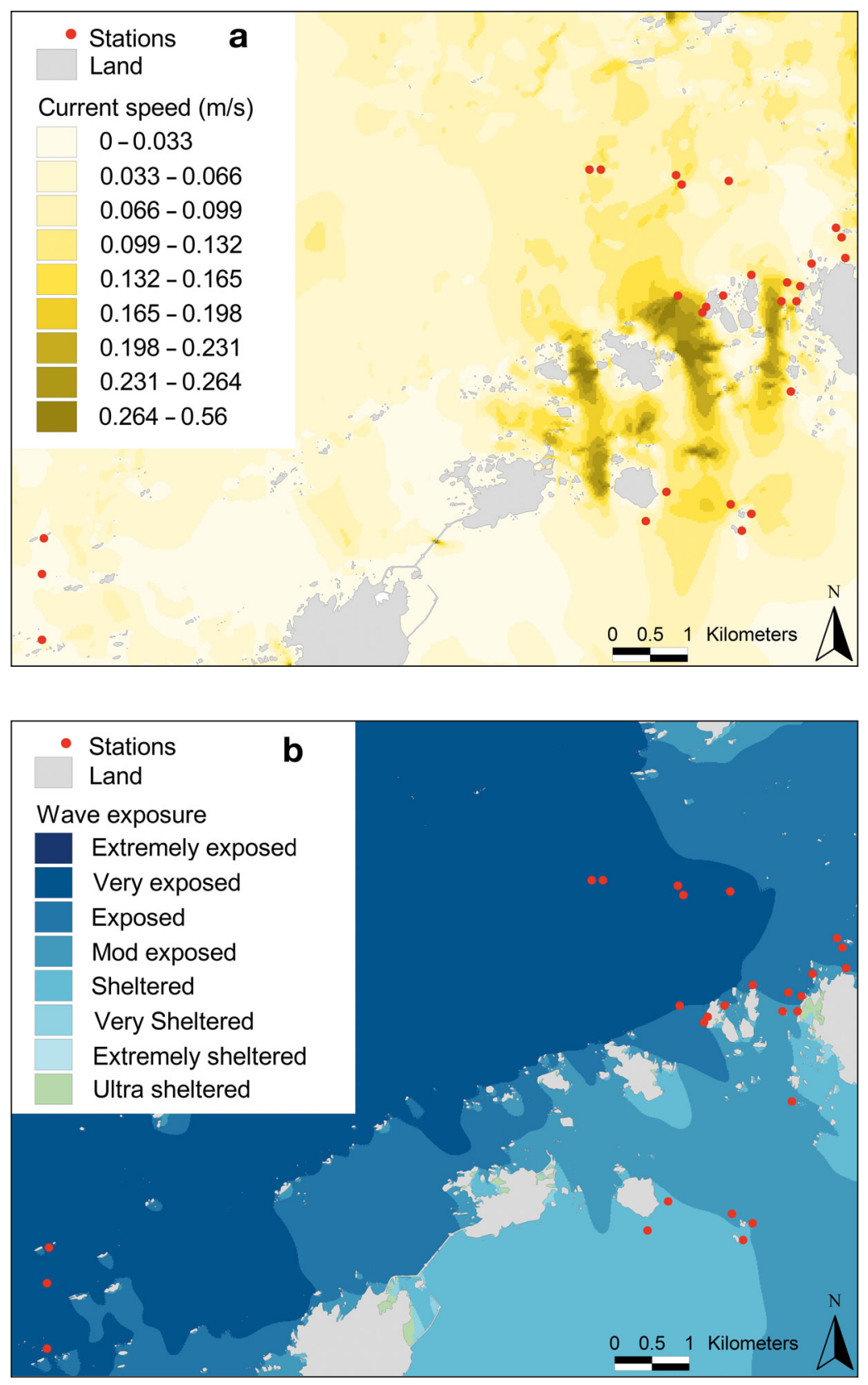

Fig. 1. Kelp Laminaria hyperborea thalli were sampled at 27 stations in the Finnøy area, in Møre og Romsdal County, on the Midwest coast of Norway $\left(62^{\circ} \mathrm{N}\right)$, along gradients of modelled (a) current speed and (b) wave exposure. The wave exposure index was modelled based on fetch, wind speed and wind frequency (Isæus 2004)

polymer, the company responsible for the harvesting within the region).

Kelp thalli were collected from the canopy layer along the gradients of modelled wave exposure and current speed, ensuring a design suitable for studying the interaction between the 2 types of water forces. At each station, we sampled 10 to 12 replicate thalli (randomly selected within the canopy layer), resulting in a total of 278 thalli. The position of each station was recorded on a GPS (Garmin GPSmap 76CSx, accuracy $\pm 5 \mathrm{~m}$ ).

We measured morphology related characters for the holdfast, stipe and lamina. Biomass for all 3 characters was measured as fresh weight. Holdfast basis length was measured at the widest part of the underside, width as a straight line perpendicular to the length line and height from the basis up to the distinct transition between holdfast and stipe. Stipe length was measured from the holdfast-stipe transition point to the distinct transition between stipe and lamina. Stipe diameter was measured immediately above the holdfast. Holdfast volume was estimated based on the stipe diameter and holdfast length, width and height measures cf. Jones (1971). Lamina length was measured as the longest straight distance from the stipe-lamina transition point. Thallus biomass and length was estimated as the sum of all 3 characters (holdfast, stipe and lamina). We estimated the proportion of the thallus biomass being stipe, holdfast and lamina, respectively. Age was determined by counting growth rings at the stipe cut surface immediately above the holdfast (cf. Kain 1963).

\section{Modelled predictor variables}

A wave exposure index was modelled (Fig. 1b, Table 1) with a spatial resolution of $10 \mathrm{~m}$ using data on fetch (distance to nearest shore, island or coast), wind speed and wind frequency (estimated as the length of time that the wind came from a specific direction, details in Isæus 2004). Data on wind speed and direction were provided by the Norwegian Meteorological Institute and averaged over $5 \mathrm{yr}$ prior to the study period. The model has been applied in several projects in Norway (e.g. Norderhaug et al. 2012, Pedersen et al. 2012), Sweden (e.g. Eriksson et al. 2004), Finland (Isæus \& Rygg 2005), the Danish 
region of the Skagerrak coast and the Russian, Latvian, Estonian, Lithuanian and German areas of the Baltic Sea (Wijkmark \& Isæus 2010).

Current speed (water column average, Fig. 1a, Table 1) was estimated using the 3-dimensional numerical ocean model ROMS (Shchepetkin \& McWilliams 2005) in a 2-level nesting procedure. Level 1: ocean currents, atmospheric forcing from forecasts by the Norwegian Meteorological Institute and climatological river flow rates were used to drive an ocean model at $500 \mathrm{~m}$ spatial resolution. Level 2: the fields from the $500 \mathrm{~m}$ model were used to drive a series of inner models, resulting in a model of $25 \mathrm{~m}$ spatial resolution. The model ROMS has shown good results when compared with field observations (LaCasce et al. 2007) and has users working both locally and globally (myroms.org).

\section{Statistical analyses}

The modelled wave exposure index and current speed values were used as continuous variables. We analysed the relative effect of wave exposure, current speed and the wave-current interaction on kelp age and the different morphology related characters. Age was included as a predictor in the analyses of morphology to control for the effect of time available for growth on kelp measures. Station was included as a random factor to avoid pseudoreplication caused by the 10 to 12 thalli sampled at each station. Residuals were assumed to be normally distributed (Gaussian family, identity link) in all models, except for the stipe, holdfast and lamina proportion, which were binomial. Log-transformation was performed to improve the normal distribution and heteroscedasticity of the residuals for all Gaussian predictor variables except stipe diameter and lamina length.

For the analyses, we used R version 2.8.1 (R Development Core Team 2008) using Generalised Additive Mixed Models (GAMMs), which are flexible and allow for non-linear relationships. The degree of freedom in the smoothing $(k)$ influences the shape, and we used $k=3$ for single predictor variables and $k=6$ for interactions. As a tool for model selection, we used the corrected Akaike's information criterion $\left(\mathrm{AIC}_{\mathrm{c} i}\right.$ Burnham et al. 2011) in the MuMIn R package (Barton 2012). The best models according to AIC are the models receiving most support from the data, but which also utilise the smallest number of explanatory factors (the principle of parsimony, i.e. the trade-off between squared bias and variance against the number of parameters in the model). We present the best
Table 1. Wave exposure index and current speed at different exposure levels of kelp. Wave exposure index model based on fetch, wind speed and wind frequency (Isæus 2004). EUNIS classes (Cameron \& Askew 2011): Low = 'Moderately exposed'; Intermediate $=$ 'Exposed' $;$ High $=$ 'Very exposed'

\begin{tabular}{|lrrrr|}
\hline \multicolumn{1}{r}{ Mean } & SD & Min. & Max. \\
\hline Wave exposure index & $\left(10^{5}\right)$ & & & \\
Low & 1.9 & 1.2 & 0.5 & 3.9 \\
Intermediate & 7.2 & 1.2 & 5.2 & 9.0 \\
High & 12.1 & 1.2 & 10.1 & 14.1 \\
Current speed $\left(\mathrm{m} \mathrm{s}^{-1}\right)$ & & & & \\
Low & 0.04 & 0.02 & 0.01 & 0.09 \\
Intermediate & 0.15 & 0.02 & 0.12 & 0.18 \\
High & 0.32 & 0.09 & 0.20 & 0.47 \\
\hline
\end{tabular}

model (the one with lowest $\mathrm{AIC}_{\mathrm{c}}$ value) and the simpler model(s) receiving good support from the data $\left(\Delta \mathrm{AIC}_{\mathrm{C}}<4\right.$, cf. Burnham et al. 2011). The relative importance (RI) of each predictor was calculated in the sum of Akaike weights over all models receiving good support from the data (Barton 2012).

\section{RESULTS}

\section{Effect of water flow on age}

The kelps sampled in the canopy layer were on average $\sim 8 \mathrm{yr}$ old (range: 4 to $13 \mathrm{yr}$, Table 2). We found no strong effects of wave and current exposure on age. However, the model was improved slightly $\left(\Delta \mathrm{AIC}_{\mathrm{C}}=0.53\right)$ by a positive effect of wave exposure on age, although this factor explained only $6 \%$ of the variance $\left(\mathrm{R}^{2}{ }_{\text {adj }}=0.06\right)$.

\section{Effect of age and water flow}

The best model for thallus biomass included (in decreasing order of importance) age, wave exposure, current speed and the interaction between wave and current (Table 3). Thallus length was best explained by age and wave exposure. The thalli became longer (Fig. 2a) and heavier (Fig. 2b) with increasing wave exposure, and biomass increased further with increasing current speed (Fig. 2b). Average biomass and length increased from $\sim 1.0 \mathrm{~kg}$ and $\sim 1.4 \mathrm{~m}$, respectively, up to average values of $\sim 3.0 \mathrm{~kg}$ and $\sim 2.5 \mathrm{~m}$ at the most exposed stations (Fig. S1 in the Supplement at www.int-res.com/articles/suppl/m506 p061_supp.pdf). The longest recorded thallus was $3.13 \mathrm{~m}$ long and the maximum recorded weight was $5.6 \mathrm{~kg}$ (Table 2). 
The model for thallus biomass and length explained 60 and $57 \%$ of the variance $\left(\mathrm{R}^{2}{ }_{\text {adj }}\right)$, respectively. Biomass was more correlated to age and wave exposure (relative importance, $\mathrm{RI}_{\text {age }}=\mathrm{RI}_{\mathrm{wave}}=1$ ) than to current speed $\left(\mathrm{RI}_{\text {current }}=0.82\right)$. Wave exposure had the highest effect on length $\left(\mathrm{RI}_{\text {wave }}=1\right)$, followed by age $\left(\mathrm{RI}_{\text {age }}=0.89\right)$. Wave exposure and current speed interacted, and the effect of current speed on thallus biomass was greater at low than at high wave exposure levels (Fig. 2b). According to $\mathrm{AIC}_{\mathrm{c}}$, the model for thallus biomass was equally good using only age and wave exposure, excluding current speed and the wave-current interaction (Table 3 ).

The stipes were on average $1.2 \mathrm{~m}$ long and $3.8 \mathrm{~cm}$ thick, weighing $1.2 \mathrm{~kg}$, with maximum values of $2.1 \mathrm{~m}, 5.8 \mathrm{~cm}$ and $3.8 \mathrm{~kg}$, respectively (Table 2 ). Stipe

Table 2. Morphology related characters of kelp Laminaria hyperborea

\begin{tabular}{|llrrrr|}
\hline & & Mean & SD & Min. & Max. \\
\hline Age (yr) & & 7.9 & 1.7 & 4 & 13 \\
Thallus & Biomass (g) & 2144.3 & 1000.9 & 421.0 & 5588.0 \\
& Length (cm) & 200.1 & 47.9 & 90.0 & 313.0 \\
Stipe & Biomass (g) & 1182.9 & 712.7 & 141.0 & 3765.0 \\
& Length (cm) & 121.2 & 39.3 & 50.0 & 206.0 \\
& Diameter (cm) & 3.8 & 0.7 & 2.1 & 5.8 \\
Holdfast & Biomass (g) & 278.6 & 131.9 & 40.0 & 813.0 \\
& Volume (cm) & 303.5 & 111.9 & 86.4 & 714.7 \\
Lamina & Biomass (g) & 688.3 & 314.8 & 94.0 & 2370.0 \\
& Length (cm) & 71.6 & 17.8 & 25.0 & 131.0 \\
Thallus bio- Stipe & 52 & 13 & 12 & 85 \\
mass (\%) & Holdfast & 13 & 4 & 3 & 35 \\
& Lamina & 35 & 12 & 6 & 69 \\
& & & & & \\
\hline
\end{tabular}

biomass and length were best explained by wave exposure and age (Table 3 ) and the stipe became both longer (Fig. 2c) and heavier (Fig. 2d) with increased wave exposure (Fig. 2). Average stipe biomass and length were $0.4 \mathrm{~kg}$ and $0.7 \mathrm{~m}$, respectively, at the most sheltered stations and $1.8 \mathrm{~kg}$ and $1.6 \mathrm{~m}$ at the most exposed stations (Fig. S1). The model for both stipe biomass and length explained $62 \%$ of the variance $\left(\mathrm{R}_{\text {adj }}^{2}\right)$. Wave exposure was the factor having the highest effect on both biomass and length $\left(\mathrm{RI}_{\text {wave }}=1\right.$ in both cases), followed by age ( $\mathrm{RI}_{\text {age }}=0.98$ and 0.76 for stipe biomass and length, respectively). According to $\mathrm{AIC}_{\mathrm{c}}$ (Table 3), the model for stipe length was equally good using wave exposure only, excluding age. No simpler model was equally good for stipe biomass. The stipe diameter was best explained by age, wave exposure, current speed and the interaction between wave and current (Table 3). The stipe got thicker with increasing wave and current speed exposure $(2.9 \mathrm{~cm}$ at the most sheltered stations and $4.5 \mathrm{~cm}$ at the most exposed stations, Fig. S1). The response levelled off at high wave exposure levels but not at high current speed levels. The effect of the increase in current speed on stipe diameter was higher (i.e. the curve was steeper) at low wave exposure than when wave exposure was high (Fig. 2e). The model explained $66 \%$ of the variance $\left(\mathrm{R}^{2}{ }_{\text {adj }}\right)$. Age and wave exposure had the highest effect $\left(\mathrm{RI}_{\text {age }}=\right.$ $\mathrm{RI}_{\text {wave }}=1, \mathrm{RI}_{\text {current }}=0.7$ ), and the simplest of the models included these 2 factors only (Table 3).

Table 3. Predictor variables (in decreasing order of importance) that, according to the corrected Akaike's information criterion $\left(\mathrm{AIC}_{\mathrm{c}}\right)$, contributed to the best models for kelp Laminaria hyperborea morphology; variance explained $\left(\mathrm{R}^{2}{ }_{\text {adj }}\right)$ in brackets

\begin{tabular}{|c|c|c|c|}
\hline & Response variable & Best model & Simpler models \\
\hline Thallus & Log(biomass) & age + wave + curr + wave $\times$ curr $(0.60)$ & $\begin{array}{l}\text { age }+ \text { wave }+ \text { curr }(0.60) \\
\text { age }+ \text { wave }(0.54)\end{array}$ \\
\hline & Log(length) & wave + age $(0.57)$ & - \\
\hline Stipe & $\begin{array}{l}\text { Log(biomass) } \\
\text { Log(length) } \\
\text { Diameter }\end{array}$ & $\begin{array}{l}\text { wave + age }(0.62) \\
\text { wave }+ \text { age }(0.62) \\
\text { age }+ \text { wave }+ \text { curr }+ \text { wave } \times \text { curr }(0.66)\end{array}$ & $\begin{array}{l}- \\
\text { wave }(0.6) \\
\text { age + wave }(0.62)\end{array}$ \\
\hline Holdfast & $\begin{array}{l}\text { Log(biomass) } \\
\text { Log(volume) }\end{array}$ & $\begin{array}{l}\text { age }+ \text { wave }+ \text { curr }+ \text { wave } \times \text { curr }(0.58) \\
\text { age }+ \text { wave }(0.38)\end{array}$ & age + wave + curr $(0.58)$ \\
\hline Lamina & $\begin{array}{l}\text { Log(biomass) } \\
\text { Length }\end{array}$ & $\begin{array}{l}\text { age }(0.16) \\
\text { curr }+ \text { wave }+ \text { age }+ \text { wave } \times \text { curr }(0.23)\end{array}$ & $\begin{array}{l}- \\
\text { curr + wave + wave } \times \text { curr }(0.21) \\
\text { curr + wave + age }(0.23) \\
\text { curr + wave }(0.21)\end{array}$ \\
\hline Thallus biomass (\%) & $\begin{array}{l}\text { Logit(stipe) } \\
\text { Logit(holdfast) } \\
\text { Logit(lamina) }\end{array}$ & $\begin{array}{l}\text { wave }(0.45) \\
\text { null model }(0.00) \\
\text { wave }(0.41)\end{array}$ & $\begin{array}{l}- \\
- \\
-\end{array}$ \\
\hline
\end{tabular}



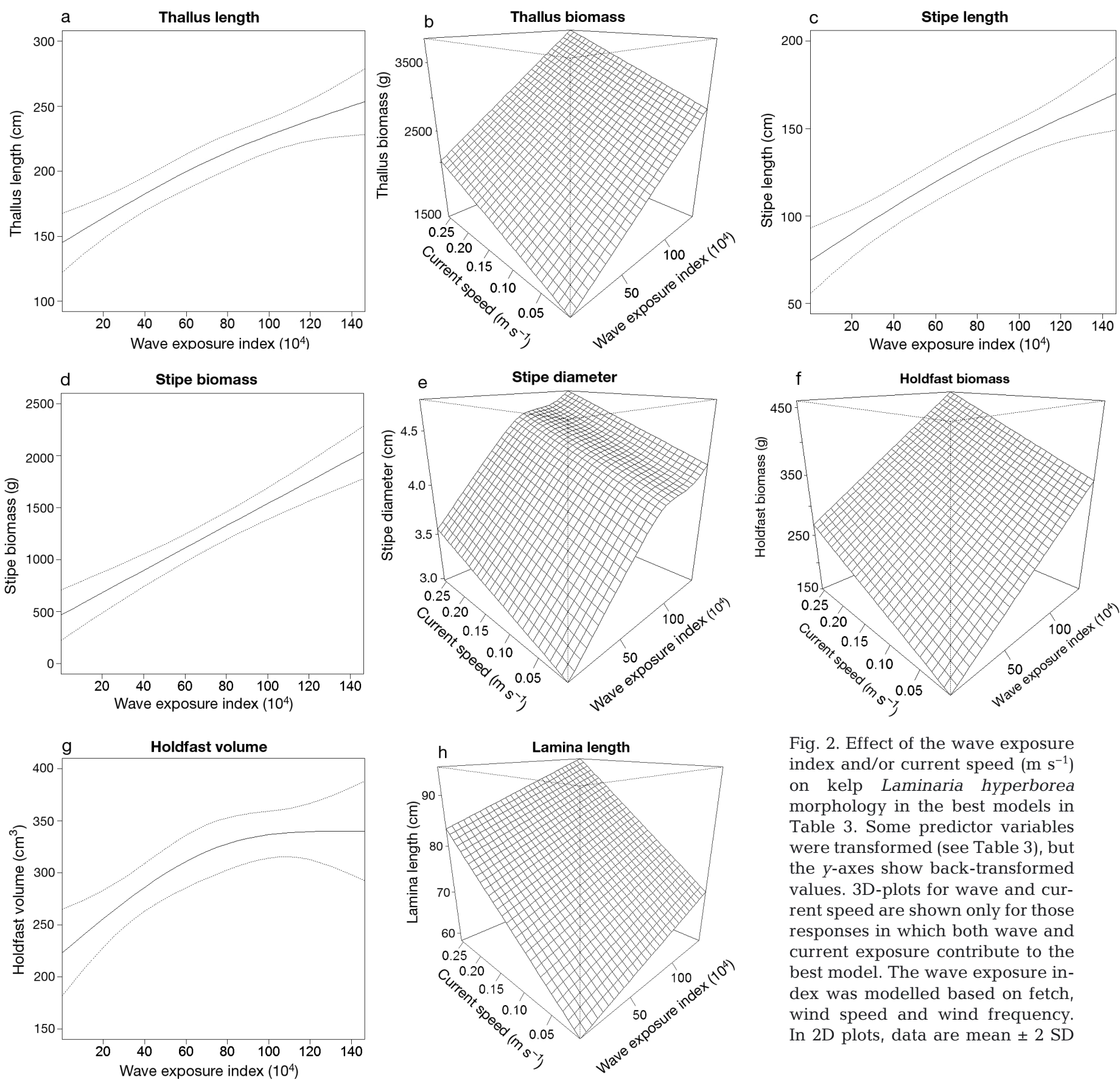

Fig. 2. Effect of the wave exposure index and/or current speed $\left(\mathrm{m} \mathrm{s}^{-1}\right)$ on kelp Laminaria hyperborea morphology in the best models in Table 3. Some predictor variables were transformed (see Table 3), but the $y$-axes show back-transformed values. 3D-plots for wave and current speed are shown only for those responses in which both wave and current exposure contribute to the best model. The wave exposure index was modelled based on fetch, wind speed and wind frequency. In $2 \mathrm{D}$ plots, data are mean $\pm 2 \mathrm{SD}$

The holdfast biomass was best explained by (in decreasing order of importance) age, wave exposure, current speed and the interaction between wave and current (Table 3). The holdfast became heavier with increasing wave exposure and current speed (Fig. 2f), with an increase in average weight from $1.3 \mathrm{~kg}$ to $3.6 \mathrm{~kg}$ from the most sheltered to the most exposed areas (Fig. S1). The best model for holdfast biomass explained $58 \%$ of the variance $\left(\mathrm{R}^{2}{ }_{\text {adj }}\right)$. Age and wave exposure had a higher effect $\left(R I_{\text {age }}=R I_{\text {wave }}=1\right)$ than current speed $\left(\mathrm{RI}_{\text {current }}=0.93\right)$, and the effect of current speed was greater at lower wave exposure levels than at high (Fig. 2f). According to $\mathrm{AIC}_{\mathrm{c}}$ (Table 3), the model for holdfast biomass was equally good without the wave-current interaction, including only age, wave exposure and current speed $\left(\mathrm{R}_{\text {adj }}^{2}=0.58\right)$. Holdfast volume was best explained by age and wave exposure (Table 3). The volume increased with increasing wave exposure, levelling off at the highest levels (Fig. $2 g, R_{\text {adj }}^{2}=0.38$ ). No simpler model was 
equally good and the inclusion of current speed did not improve the model. Age had a higher effect $\left(\mathrm{RI}_{\text {age }}=1\right)$ than wave exposure $\left(\mathrm{RI}_{\text {wave }}=0.96\right)$ on holdfast volume.

Age was the only factor determining lamina biomass (Table 3), i.e. there was no effect of increases in wave and current exposure levels. Lamina length was best explained by current speed, wave exposure, age and the interaction between wave and current (Table 3, Fig. 2h). However, the models were poor, explaining only 16 and $23 \%$ of the variation in the lamina biomass and length model respectively.

The biomass of the kelp thallus consisted of, on average, $52 \%$ stipe, $35 \%$ lamina and 13\% holdfast (Table 2). The proportion of stipe increased at the expense of lamina with increasing wave exposure (Table 3), from on average of $40 \%$ (stipe) and $47 \%$ (lamina) in the most sheltered areas to $61 \%$ (stipe) and $27 \%$ (lamina) in the most exposed areas $\left(\mathrm{R}^{2}{ }_{\text {adj, stipe }}=0.45, \mathrm{R}_{\text {adj, lamina }}^{2}=0.41\right.$, Fig. $\left.\mathrm{S} 1\right)$. The proportion of the thallus biomass being holdfast was not influenced by age or the different levels of waves and currents.

\section{DISCUSSION}

High water flow, in respect to both wave exposure and current speed, resulted in strength-related responses, i.e. robust holdfasts and thick stipes. Overall, the orbital and stochastic wave forces had a stronger effect than the more regular and bidirectional tidal driven current forces. Furthermore, the 2 water forces interacted, and increased current speed had a clear effect at low levels of wave exposure, but had a weaker effect at high wave exposure levels. The length-related characters (i.e. thallus and stipe length) increased with greater wave induced water flow, but no effect of increased current exposure was found. Variation in water flow generally had little influence on lamina measures, but the proportion of the thallus being lamina was highest in more sheltered areas and decreased as wave exposure increased. The variability in morphology allows L. hyperborea to grow and successfully dominate areas with different water flow regimes. Strong holdfasts and robust stipes are important adaptations to water flow, and allow the kelp to utilise areas with high nutrient transport and little epiphytic growth on the lamina without being broken or completely removed from the substrate (as also observed by e.g. Sjøtun \& Fredriksen 1995, Wernberg \& Vanderklift 2010).
L. hyperborea growth mainly takes place in winter and early spring, more or less ceasing during summer, when nutrient levels are low (Lüning 1979, Sjøtun et al. 1996). Hepburn et al. (2007) found that the effect of water flow on kelp growth varied with seasonal variation in nutrient availability. Consequently, our results on lamina measures may be season specific and might change if studied in another season. However, stipe and holdfast reflect the cumulative growth of several years.

\section{Length-related characters}

Stipes were on average $1.21 \mathrm{~m}$ long (range: 0.50 to $2.06 \mathrm{~m}$ ). The stipe length increased with increasing wave exposure, being on average about twice as long in the most exposed areas compared to the most sheltered ones, as reported for both L. hyperborea (Sjøtun et al. 1998, Pedersen et al. 2012) and other kelp species (e.g. Wernberg \& Thomsen 2005, Wernberg \& Vanderklift 2010). This is most likely an adaptation to the wave exposure, as a long and flexible thallus can 'go with the flow' and reduce the impact from hydrodynamic forces caused by the orbital and stochastic waves (Friedland \& Denny 1995, Denny et al. 1998, Koehl 1999). The high wave exposure will also provide improved conditions for growth, as the water flow increases the light influx on the lamina (Lobban \& Harrison 1994) and reduces the boundary diffusion layer, which increases nutrient uptake (Gerard 1982, Hurd et al. 1996). The lack of response in length-related characters to the different levels of current exposure supports the 'go with the flow'theory, as this force is more regular than the orbital and stochastic forces associated with wave exposure. The stipes in our study were longer that those of Pedersen et al. (2012), collected in the canopy layer within the same area. An explanation for this difference is most likely that we sampled from a wider range of wave exposures (Table 1 compared to Table 1 in Pedersen et al. 2012).

We found a linear relationship between thallus and stipe length and wave exposure. This relationship may have levelled off, or even have been bellshaped, if we had included even more exposed stations in our study, i.e. we may have found a reduction in stipe length at extremely high exposure levels due to the cost of developing a thicker stipe (to avoid breakage). Fowler-Walker et al. (2006) suggested that inconsistencies among studies reflect such nonlinear relationships, e.g. a positive relationship in the sheltered areas and a negative relationship in the 
more exposed areas. This underpins the need for analyses of continuous, not categorical relationships, which is also stressed by Wernberg \& Thomsen (2005) and Wernberg \& Vanderklift (2010). As the exposure values of different studies are often not comparable, this has been difficult to assess. Even though our study area had a wide range of exposure levels, Røv et al. (1990) and unpublished field observations report stipes to be very short under extremely exposed conditions.

We observed only weak relationships between the different levels of water flow and lamina measures. This is in contrast to many studies finding thicker and more streamlined fronds in exposed than in sheltered areas (e.g. Wernberg \& Vanderklift 2010, Miller et al. 2011). Fowler-Walker et al. (2006) suggested that stressors typical of sheltered areas (i.e. related to diffusion) are not as influential as the stressors typical of exposed environments (i.e. breakage and dislodgement) when it comes to differentiating morphology along exposure gradients. However, we only measured lamina biomass and length, not shape and thickness, as was measured by the others. We found that a smaller proportion of the thallus biomass was allocated to the lamina when wave exposure increased (almost half of the thallus was lamina in the most exposed compared to the most sheltered areas). This indicates that adaptations to stress induced by water flow, such as strength-related responses, occur at the cost of lamina growth. However, lamina length and biomass are difficult to assess correctly, as parts of the lamina might be lost due to water forces or even the handling of the thallus during sampling.

\section{Strength-related characters}

Adaption of kelp to strong water forces prevents breakage and dislodgement (e.g. Sjøtun \& Fredriksen 1995, Wernberg \& Vanderklift 2010). We found that kelp developed on average a 1.6 times thicker stipe and a more than 3 times heavier holdfast in high water flow areas compared to the most sheltered ones. Our findings show typical strength-increasing responses and are in accordance with other studies, showing that kelp have thicker stipes and are more firmly attached to the substrate in high compared to low exposure areas (e.g. Sjøtun \& Fredriksen 1995, Duggins et al. 2003, Koehl et al. 2008, Wernberg \& Vanderklift 2010).

Overall, the effect of wave exposure was stronger than that of current speed. This might be explained by differences in the mode of the 2 water forces re- sulting in stronger strength-induced responses from waves than from currents. This is supported by Miller et al. (2011), who found stronger morphological adaptations in areas with higher and more orbital wave action compared to areas dominated by unidirectional currents. Kain (1971b) suggested that different responses in kelp morphology occur in high current and in high wave exposed levels, but few have quantified the relative importance of the 2 water forces (but see Eckman et al. 2003). The interaction between wave exposure and current speed implies that an increase in current speed had a considerable effect at low wave exposure, but not at high wave exposure levels. The weak influence of current speed might also be a response to the difference in magnitude in water velocity generated by the 2 water flow mechanisms, as the waves in the area might generate higher water flow than the currents. Lobban \& Harrison (1994) consider that steady currents of $0.5 \mathrm{~m} \mathrm{~s}^{-1}$, which is the maximum modelled in our study, are generally strong, but weak compared to velocities of breaking waves. As the current driven water flow is not as orbital, it might also result in more kelp self-shading at high current speeds compared to high wave exposure. This is supported by Stevens et al. (2003), who suggested that it is the mode of the water motion, not the relative velocity at the lamina surface, which results in the morphological differences.

\section{CONCLUSIONS}

The kelp forest is a highly productive system. An important ecological function of a kelp forest is as a habitat for high numbers of species and individuals of epiphytic algae and associated invertebrates and fish (Whittick 1983, Christie et al. 2003, Norderhaug et al. 2005). The importance of Laminaria hyperborea as a habitat is very much related to size and structural complexity (Christie et al. 2003, Norderhaug et al. 2007), as long and thick stipes provide large areas on which epiphytic algae and associated fauna species may attach. Large holdfasts provide large benthic habitats (Christie et al. 2003). This shows that the structure of the kelp forest has a very important function facilitating cascading habitat formation, which is recognised in both terrestrial and marine studies (see review in Thomsen et al. 2010).

Acknowledgements. The project was funded by the HAVKYST program of the Research Council of Norway ('KelpPredict', project nr. 184638, 2008-2012) and the Norwegian Institute for Water Research (NIVA). We thank Martin Isæus 
(AquaBiota Water Research, Sweden) for the wave exposure modelling, André Staalstrøm (NIVA) for the current speed modelling, Kate Hawley (NIVA) for proofreading and the staff at Finnøy Sjøhus for taking good care of us during fieldwork.

\section{LITERATURE CITED}

Barton K (2012) MuMIn: Multi-model inference R package version 1.7.7. cran.r-project.org/web/packages/MuMIn/ index.html

> Bartsch I, Wiencke C, Bischof K, Buchholz CM and others (2008) The genus Laminaria sensu lato: recent insights and developments. Eur J Phycol 43:1-86

Bekkby T, Isachsen PE, Isæus M, Bakkestuen V (2008) GIS modeling of wave exposure at the seabed: a depth-attenuated wave exposure model. Mar Geod 31:117-127

Bekkby T, Rinde E, Erikstad L, Bakkestuen V (2009) Spatial predictive distribution modelling of the kelp species Laminaria hyperborea. ICES J Mar Sci 66:2106-2115

Burnham KP, Anderson DR, Huyvaert K (2011) AIC model selection and multimodel inference in behavioral ecology: some background observations and comparisons. Behav Ecol Sociobiol 65:23-35

Cameron A, Askew N (2011) EUSeaMap - preparatory action for development and assessment of a European broad-scale seabed habitat map final report. jncc.gov. uk/euseamap

Christie H, Jørgensen NM, Norderhaug KM, Waage-Nielsen E (2003) Species distribution and habitat exploitation of fauna associated with kelp (Laminaria hyperborea) along the Norwegian coast. J Mar Biol Assoc UK 83:687-699

> Denny MW, Gaylord BP, Helmuth B, Daniel T (1998) The menace of momentum: dynamic forces on flexible organisms. Limnol Oceanogr 43:955-968

> Duggins DO, Eckman JE, Siddon CE, Klinger T (2003) Population, morphometric and biomechanical studies of three understory kelps along a hydrodynamic gradient. Mar Ecol Prog Ser 265:57-76

> Eckman JE, Duggins DO, Siddon CE (2003) Current and wave dynamics in the shallow subtidal: implications to the ecology of understory and surface-canopy kelp. Mar Ecol Prog Ser 265:45-56

Eriksson BK, Sandström A, Isæus M, Schreiber H, Karås P (2004) Effects of boating activities on aquatic vegetation in the Stockholm Archipelago, Baltic Sea. Estuar Coast Shelf Sci 61:339-349

Fowler-Walker MJ, Wernberg T, Connell SD (2006) Differences in kelp morphology between wave sheltered and exposed localities: morphologically plastic or fixed traits? Mar Biol 148:755-767

> Friedland MT, Denny MW (1995) Surviving hydrodynamic forces in a wave-swept environment-consequences of morphology in the feather boa kelp, Egregia menziesii (Turner). J Exp Mar Biol Ecol 190:109-133

Gerard VA (1982) In situ water motion and nutrient uptake by the giant kelp Macrocystis pyrifera. Mar Biol 69:51-54

Gorman D, Bajjouk T, Populus J, Vasquez M, Ehrhold A (2013) Modeling kelp forest distribution and biomass along temperate rocky coastlines. Mar Biol 160:309-325

Hepburn CD, Holborow JD, Wing SR, Frew RD, Hurd CL (2007) Exposure to waves enhances the growth rate and nitrogen status of the giant kelp Macrocystis pyrifera. Mar Ecol Prog Ser 339:99-108
Hurd CL (2000) Water motion, marine macroalgal physiology, and reproduction. J Phycol 36:453-472

> Hurd CL, Harrison PJ, Druehl LD (1996) Effect of seawater velocity on inorganic nitrogen uptake by morphologically distinct forms of Macrocystis integrifolia from wave-sheltered and exposed sites. Mar Biol 126:205-214

> Hymanson ZP, Reed DC, Foster MS, Carter JW (1990) The validity of using morphological characteristics as predictors of age in the kelp Pterygophora californica (Laminariales, Phaeophyta). Mar Ecol Prog Ser 59:295-304

Isæus M (2004) Factors structuring Fucus communities at open and complex coastlines in the Baltic Sea. PhD dissertation, Department of Botany, Stockholm University

Isæus M, Rygg B (2005) Wave exposure calculations for the Finnish coast. NIVA report 5075, Oslo

Jones DJ (1971) Ecological studies on macroinvertebrate populations associated with polluted kelp forests in the North Sea. Helgol Wiss Meeresunters 22:417-441

Kain JM (1963) Aspects of the biology of Laminaria hyperborea. II. Age, weight and length. J Mar Biol Assoc UK 43:129-151

Kain JM (1971a) The biology of Laminaria hyperborea. VI. Some Norwegian populations. J Mar Biol Assoc UK 51: 387-408

Kain JM (1971b) Synopsis of biological data on Laminaria hyperborea. FAO Fish Synop 87

> Koehl MAR (1999) Ecological biomechanics: life history, mechanical design, and temporal patterns of mechanical stress. J Exp Biol 202:3469-3476

Koehl MAR, Silk WK, Liang H, Mahadevan L (2008) How kelp produce blade shapes suited to different flow regimes: a new wrinkle. Integr Comp Biol 48:834-851

> Kregting L, Blight A, Elsäßer B, Savidge G (2013) The influence of water motion on the growth rate of the kelp Laminaria hyperborea. J Exp Mar Biol Ecol 448:337-345

LaCasce JH, Røed LP, Bertino L, Ådlandsvik B (2007) CONMAN technical report no. 2: analysis of model results, met.no Report 5/2007. Norwegian Meteorological Institute, Oslo

Lobban CS, Harrison PJ (1994) Seaweed ecology and physiology. Cambridge University Press, Cambridge

Lüning K (1979) Growth strategies of three Laminaria species (Phaeophyceae) inhabiting different depth zones in the sublittoral region of Helgoland (North Sea). Mar Ecol Prog Ser 1:195-207

Mann KH (2000) Ecology of coastal waters. Blackwell, Malden, MA

- Martone PT, Kost L, Boller M (2012) Drag reduction in waveswept macroalgae: alternative strategies and new predictions. Am J Bot 99:806-815

> Miller SM, Hurd CL, Wing SR (2011) Variations in growth, erosion, productivity, and morphology of Ecklonia radiata (Alariaceae; Laminariales) along a fjord in southern New Zealand. J Phycol 47:505-516

> Norderhaug KM, Christie H, Fosså JH, Fredriksen S (2005) Fish-macrofauna interactions in a kelp (Laminaria hyperborea) forest. J Mar Biol Assoc UK 85:1279-1286

Norderhaug KM, Christie H, Fredriksen S (2007) Is habitat size an important factor for faunal abundances on kelp (Laminaria hyperborea)? J Sea Res 58:120-124

> Norderhaug KM, Christie H, Andersen GS, Bekkby T (2012) Does the diversity of kelp forest macrofauna increase with wave exposure? J Sea Res 69:36-42

Pedersen MF, Nejrup LB, Fredriksen S, Christie H, Norderhaug KM (2012) Effects of wave exposure on population 
structure, demography, biomass and productivity in kelp Laminaria hyperborea. Mar Ecol Prog Ser 451:45-60

R Development Core Team (2008) R: A language and environment for statistical computing. R Foundation for Statistical Computing, Vienna (www.R-project.org)

Raven JA (1981) Nutritional strategies of submerged benthic plants: the acquisition of $\mathrm{C}, \mathrm{N}$ and $\mathrm{P}$ by rhizophytes and haptophytes. New Phytol 88:1-30

Raven JA (1988) Algae on the move. Trans Bot Soc Edinb 45: 167-186

Rinde E, Sjøtun K (2005) Demographic variation in the kelp Laminaria hyperborea along a latitudinal gradient. Mar Biol 146:1051-1062

Røv N, Christie H, Fredriksen S, Leinaas HP, Lorentsen SH (1990) A preliminary investigation on the possible effects of seaweed trawling in Sør-Trøndelag County. NINA Oppdragsmeld 52:1-20 (in Norwegian with English Abstract)

Schoschina EV (1997) On Laminaria hyperborea (Laminariales, Phaeophyceae) on the Murman coast of the Barents Sea. Sarsia 82:371-373

Shchepetkin AF, McWilliams JC (2005) Regional ocean model system: a split-explicit ocean model with a free surface and topography-following vertical coordinate. Ocean Model 9:347-404

Sjøtun K, Fredriksen S (1995) Growth allocation in Laminaria hyperborea (Laminariales, Phaeophyceae) in relation to age and wave exposure. Mar Ecol Prog Ser 126: 213-222

Sjøtun K, Fredriksen S, Rueness J (1996) Seasonal growth and carbon and nitrogen content in canopy and first-year plants of Laminaria hyperborea (Laminariales, Phaeophyceae). Phycologia 35:1-8

Sjøtun K, Fredriksen S, Rueness J (1998) Effect of canopy biomass and wave exposure on growth in Laminaria hyperborea (Laminariaceae: Phaeophyta). Eur J Phycol 33:337-343

Editorial responsibility: Lisandro Benedetti-Cecchi, Pisa, Italy
Stevens CL, Hurd CL, Isachsen PE (2003) Modelling of diffusion boundary-layers in subtidal macroalgal canopies: the response to waves and currents. Aquat Sci 65:81-91

Sultan S (2001) Phenotypic plasticity for fitness components in polygonum species of contrasting ecological breadth. Ecology 82:328-343

Svendsen P, Kain JM (1971) The taxonomic status, distribution, and morphology of Laminaria cucullata sensu Jorde and Klavestad. Sarsia 46:1-22

> Thomsen MS, Wernberg T, Altieri A, Tuya F and others (2010) Habitat cascades: the conceptual context and global relevance of facilitation cascades via habitat formation and modification. Integr Comp Biol 50:158-175

Vadas RL, Wright WA, Miller SL (1990) Recruitment of Ascophyllum nodosum: wave action as a source of mortality. Mar Ecol Prog Ser 61:263-272

> Wernberg T (2005) Holdfast aggregation in relation to morphology, age, attachment and drag for the kelp Ecklonia radiata. Aquat Bot 82:168-180

> Wernberg T, Thomsen MS (2005) The effect of wave exposure on the morphology of Ecklonia radiata. Aquat Bot 83:61-70

- Wernberg T, Vanderklift MA (2010) Contribution of temporal and spatial components to morphological variation in the kelp Ecklonia (Laminariales). J Phycol 46:153-161

Wheeler WN (1988) Algal productivity and hydrodynamics - a synthesis. Prog Phycol Res 6:23-58

> Whittick A (1983) Spatial and temporal distributions of dominant epiphytes on the stipes of Laminaria hyperborea (Gunn.) Fosl. (Phaetophyta: Laminariales) in S.E. Scotland. J Exp Mar Biol Ecol 73:1-10

Wijkmark N, Isæus M (2010) Wave exposure calculations for the Baltic Sea. AquaBiota report 2, Stockholm

Wing SR, Patterson MR (1993) Effects of wave-induced light flecks in the intertidal zone on photosynthesis in the macroalgae Postelsia palmaeformis and Hedophyllum sessile (Phaeophyceae). Mar Biol 116:519-525

Submitted: April 17, 2013; Accepted: February 27, 2014 Proofs received from author(s): June 2, 2014 